\title{
High Flow Nasal Cannula in Pediatric Intensive Care Unit: Still an Open Question [Letter]
}

\author{
Bshayer Ramadan Alhamad ${ }^{1,2}$ \\ Antonio M Esquinas (D) $^{3}$ \\ 'Department of Respiratory Therapy, \\ College of Applied Medical Sciences, King \\ Saud bin Abdulaziz University for Health \\ Sciences, Al Ahsa, Saudi Arabia; ${ }^{2}$ King \\ Abdullah International Medical Research \\ Center, Al Ahsa, Saudi Arabia; ${ }^{3}$ Intensive \\ Care Unit, Hospital Morales Meseguer, \\ Murcia, Spain
}

\section{Dear editor}

We have read with great interest the article published by Asseri et al which explores the indications and safety of high flow nasal cannula (HFNC) use in Pediatric Intensive Care Unit (PICU) and determine the predictors of its failure in Saudi Arabia. ${ }^{1}$

The study identified positive clinical characteristics and laboratory tests in most of the children after 8 hour of the use of HFNC in pediatric patients and the main indications used were respiratory distress secondary to bronchopneumonia, bronchiolitis, status asthmaticus, and post-extubation. The failure of HFNC was found in one fourth of the patients participated in the study. ${ }^{1}$ However, we believe certain aspects of this study need to be addressed.

First, the study defined HFNC success in pediatric by the improvement seen in vital signs and laboratory tests after 8 hour and 48 hour of HFNC use. However, it has not mentioned based on what evidence 8 hour and 48 hour has been selected.

Secondly, the study assessed the age, gender, associated chronic diseases, indications of HFNC, previous admission to ICU along with other parameters, but it did not assess the size/weight of the patient. The distending airway pressure caused by HFNC appears to be dependent on the weight of the patient since the flow rate can be estimated by the patient's weight with starting tolerating flow rate of $1-2 \mathrm{~L} / \mathrm{kg} / \mathrm{min}$, followed by an increase of $0.5 \mathrm{~L} / \mathrm{kg} / \mathrm{min}$ for patients younger than 24 months of age. ${ }^{2,3}$ Feldman et $\mathrm{al}^{4}$ found that weight can be considered as a factor to determine the success or failure of using HFNC. They reported that pediatric patient whose age is less than 2 year-old and weighed $>5 \mathrm{~kg}$ were 2.6 times more likely to succeed on the pediatric ward compared with those weighing $<5 \mathrm{~kg}$ (aOR: 2.6 (CI 1.3-5.2, $<<0.01$ ).

Third, from methodology point of view, we consider relevant that authors could describe the range of flow rate that has been used for HFNC in the study. It only stated that the maximum flow rate was $30 \mathrm{~L} / \mathrm{min}$ according to the international guidelines of HFNC in pediatric patients. Knowing the flow rate range is important since the positive distending pressure will increase as the flow rate increases which may help to explore the causes of complications like air leak syndrome that occurs in some patients in the study. ${ }^{2}$ It also did not mention the manufacture of the HFNC and its characteristics like the diameter of nasal cannula being used, which is considered as a factor that increases the distending airway pressure caused by HFNC. ${ }^{2} \mathrm{Kwon}^{3}$ summarized the recommended flow rate and cannula size of HFNC for pediatric patients in his article.

In regards to data analysis, the study did not mention if Levene's homogeneity test has been assessed before comparing the HFNC failure group with that of HFNC non- 
failure group when independent $t$-test was used to make sure that the two groups were similar in the baseline data. It will be interesting also to subdivide the group using HFNC based on the primary diagnosis and compared it with the other group who have the same primary diagnosis but have not used HFNC.

In conclusion, addressing these points will help bolster the results and further clinical trials are needed to confirm the observations of this study.

\section{Disclosure}

The authors report no conflicts of interest in this communication.

\section{References}

1. Asseri AA, AlQahtani YA, Alhanshani AA, Ali GH, Alhelali I. Indications and safety of high flow nasal cannula in pediatric intensive care unit: retrospective single center experience in Saudi Arabia. Pediatric Health Med Ther. 2021;12:431-437. doi:10.2147/PHMT. S321536

2. Mikalsen IB, Davis P, Øymar K. High flow nasal cannula in children: a literature review. Scand J Trauma Resusc Emerg Med. 2016;24:93. doi:10.1186/s13049-016-0278-4

3. Kwon JW. High-flow nasal cannula oxygen therapy in children: a clinical review. Clin Exp Pediatr. 2020;63(1):3-7. doi:10.3345/ kjp.2019.00626

4. Feldman JD, Zusman AS, Chaudry TE, Lyon LI. Postlethwaite, DA. Safety and efficacy of high flow nasal cannula use on pediatric wards. Pediatrics.2019;144(2_Meeting Abstract):402. doi:10.1542/peds.144.2MA 5.402

\begin{abstract}
Dove Medical Press encourages responsible, free and frank academic debate. The content of the Pediatric Health, Medicine and Therapeutics 'letters to the editor' section does not necessarily represent the views of Dove Medical Press, its officers, agents, employees, related entities or the Pediatric Health, Medicine and Therapeutics editors. While all reasonable steps have been taken to confirm the content of each letter, Dove Medical Press accepts no liability in respect of the content of any letter, nor is it responsible for the content and accuracy of any letter to the editor.
\end{abstract}

Pediatric Health, Medicine and Therapeutics

\title{
Dovepress
}

\section{Publish your work in this journal}

Pediatric Health, Medicine and Therapeutics is an international, peerreviewed, open access journal publishing original research, reports, editorials, reviews and commentaries. All aspects of health maintenance, preventative measures and disease treatment interventions are addressed within the journal. Practitioners from all disciplines are invited to submit their work as well as healthcare researchers and patient support groups. The manuscript management system is completely online and includes a very quick and fair peer-review system. Visit http://www.dovepress.com/testimonials.php to read real quotes from published authors. 